\title{
Mechanism of systolic anterior motion of mitral valve and site of intraventricular pressure gradient in hypertrophic obstructive cardiomyopathy
}

\author{
SEIKI NAGATA, YASUHARU NIMURA, SHINTARO BEPPU, YUNG-DAE PARK, \\ HIROSHI SAKAKIBARA \\ From the Department of Medicine, Division of Cardiology, and Research Institute, National Cardiovascular Center, \\ Suita, Osaka, fapan
}

SUMMARY The mechanism of systolic anterior motion of the mitral valve and the localisation of the intraventricular pressure gradient were determined in 15 cases of hypertrophic obstructive cardiomyopathy by the combined use of real time two dimensional echocardiography and intracardiac $₹$ manometry. We arrived at the following conclusions. The systolic anterior motion of the mitral echo in the M-mode echocardiogram can be classified into two types, I and II, based on two dimensional echocardiographic findings. In type I, the echo sources of systolic anterior motion are the anteriorly $\vec{\otimes}$ shifted mitral chordae and, in part, the papillary muscles. The intraventricular pressure gradient occurs at the level of the tip of the papillary muscle. The suprapapillary part of the outflow tract and the inflow part show a low pressure, while the apical cavity shows a high pressure. In type II, the echo sources of systolic anterior motion are the anterior and posterior mitral leaflets which are oriented in such a way as to obstruct the outflow tract. The pressure gradient occurs at the level of $\frac{\mathscr{D}}{\Phi}$ the anterior and posterior mitral leaflets. The inflow tract and the outflow tract just below the mitral $\stackrel{\varrho}{\Rightarrow}$ leaflets show a high pressure, in contrast to type I systolic anterior motion. The inappropriate and $\frac{\mathrm{O}}{3}$ maloriented papillary muscles play an essential role in causing both types of systolic anterior motion and outflow obstruction. The direction of the axis of the papillary muscle is changed in late systole, moving its tip away from the interventricular septum, resulting in a simultaneous reduction in systolic anterior motion.

A possible relation between the systolic anterior motion of the mitral valve on the M-mode echocardiogram and the intraventricular pressure gradient in hypertrophic cardiomyopathy has been suggested. ${ }^{1}$ The localisation of the pressure gradient, however, has not been clearly determined and cases often have systolic anterior motion of the mitral valve but no intraventricular pressure gradient. ${ }^{2}$ New techniques of cardiological investigation have made available further detailed information on anatomical and dynamic features of intracardiac events. In the present study, an attempt was made to analyse the mechanisms of the systolic anterior motion of the mitral valve, and the intraventricular pressure gra-

This study was supported in part by a "Research Grant for Research of Idiopathic Cardiomyopathy" from the Ministry of Health and Welfare, Japan, in 1980-1982.

Accepted for publication 28 September 1982 dient, and the relation between them, using real time two dimensional echocardiography and intraventricular manometry.

\section{Patients and methods}

The subjects studied were 15 patients (10 men, five women, Table) with hypertrophic obstructive car-요 diomyopathy. Their ages ranged from 28 to 53 years $\omega$ (average 42). The diagnosis was made in each bye routine examinations, M-mode echocardiography, real time two dimensional echocardiography, and left ventriculography, including intraventricular man-ometry (Table). Systolic anterior motion of the mitrat valve could be seen on the $M$-mode echocardiogram in all.

We used commercially available real time two dimensional echocardiographs of a wide angle phase 
Table Identification of patients examined and their echocardiographic and haemodynamic conditions

\begin{tabular}{|c|c|c|c|c|c|c|c|c|}
\hline \multirow[b]{2}{*}{ Case No. } & \multirow[b]{2}{*}{ Age } & \multirow[b]{2}{*}{ Sex } & \multicolumn{4}{|l|}{ Echo } & \multicolumn{2}{|c|}{ Pressure gradient ( $\mathrm{mmHg}$ ) } \\
\hline & & & IVS & Post. wall & $I V S / P W$ & $S A M$ & $\begin{array}{l}\text { Papillary } \\
\text { muscle site }\end{array}$ & Leaflet site \\
\hline $\begin{array}{r}1 \\
2 \\
3 \\
4 \\
5 \\
6 \\
7 \\
8 \\
9 \\
10 \\
11 \\
12 \\
13 \\
14 \\
15\end{array}$ & $\begin{array}{l}39 \\
48 \\
44 \\
50 \\
41 \\
49 \\
38 \\
35 \\
48 \\
53 \\
33 \\
28 \\
43 \\
39 \\
35\end{array}$ & $\begin{array}{l}\mathbf{M} \\
\mathbf{M} \\
\mathbf{M} \\
\mathbf{M} \\
\mathbf{F} \\
\mathbf{M} \\
\mathbf{M} \\
\mathbf{M} \\
\mathbf{F} \\
\mathbf{F} \\
\mathbf{F} \\
\mathbf{F} \\
\mathbf{M} \\
\mathbf{M} \\
\mathbf{M}\end{array}$ & $\begin{array}{l}24 \\
28 \\
28 \\
34 \\
22 \\
26 \\
20 \\
40 \\
32 \\
36 \\
18 \\
19 \\
36 \\
20 \\
25\end{array}$ & $\begin{array}{r}12 \\
16 \\
10 \\
20 \\
9 \\
12 \\
10 \\
12 \\
11 \\
22 \\
12 \\
17 \\
15 \\
10 \\
10\end{array}$ & $\begin{array}{l}2.0 \\
1.8 \\
2.8 \\
1.7 \\
2.4 \\
2.2 \\
2.0 \\
3.3 \\
2.9 \\
1.6 \\
1.5 \\
1.1 \\
2.4 \\
2.0 \\
2.5\end{array}$ & $\begin{array}{l}\text { I } \\
\text { I } \\
\text { I } \\
\text { I } \\
\text { I } \\
\text { I } \\
\text { I } \\
\text { Inter. } \\
\text { Inter. } \\
\text { II } \\
\text { II } \\
\text { II } \\
\text { II } \\
\text { II } \\
\text { II }\end{array}$ & $\begin{array}{l}90 \\
50 \\
50 \\
30 \\
? \\
? \\
? \\
? \\
? \\
? \\
? \\
? \\
? \\
? \\
?\end{array}$ & $\begin{array}{r}0 \\
0 \\
0 \\
0 \\
0 \\
0 \\
0 \\
28 \\
11 \\
14 \\
0 \\
108 \\
86 \\
0 \\
0\end{array}$ \\
\hline
\end{tabular}

array system, Toshiba SSH-11A and Aloka SSD-800. The moving images were recorded on $8 \mathrm{~mm}$ cine film, and the instantaneous still images were also recorded by an electrocardiograph gated mechanism. The above equipment was designed to produce simultaneous displays of the cardiac image and intraventricular pressure on the screen. Intraventricular manometry was done using catheters with a Millar micro-tip pressure transducer and fluid filled.

Real time two dimensional echocardiography was conventionally performed for the analysis of motion of the intracardiac structures mainly from the parasternal approach, with the patient supine. The development of systolic anterior motion of the mitral echo was examined by observing serial images of the intracardiac structures in the long axis and short axis views.

Real time two dimensional echocardiography was also performed during cardiac catheterisation to determine the spatial location of the catheter tip in the left ventricular cavity. The relations between the catheter tip and the intracardiac structures were ascertained to determine the site of the intraventricular pressure gradient. For this, it was necessary to confirm that the catheter tip was kept in the crosssectional plane and the following procedure was followed step by step: (1) the left ventricular outflow tract was searched for the catheter echo in the long axis image; (2) the catheter echo was followed toward the apical side by tilting and rotating the transducer to keep the catheter echo within the image; (3) when what appeared to be the end of the catheter was identified, it was confirmed in the short axis view that no catheter echo was detected at the levels below the end of the catheter echo which was, therefore, the tip echo; (4) a new long axis plane was fixed by rotating the transducer, keeping the catheter tip in the image, and then the relations between the catheter tip and the surrounding cardiac structures were determined;
(5) the above procedures were repeated to confirm the reproducibility of these findings. The Millar tip pressure transducer also had advantages in that the tip yielded a more intense echo than did the rest of the catheter and was therefore easily recognised. The pressure changes when the end of the catheter echo passed through the aortic orifice or touched the ventricular wall were often useful references for confirming that the end of the catheter echo was indeed the tip echo.

\section{Results}

DEVELOPMENT OF SYSTOLIC ANTERIOR MOTION OF MITRAL ECHO IN M-MODE ECHOCARDIOGRAM, AS SEEN BY REAL TIME TWO DIMENSIONAL ECHOCARDIOGRAPHY

The morphological and dynamic features of the mitral leaflets, chordae, and the papillary muscles were followed in the serial images of the left ventricle through one cardiac cycle.

One or both of the papillary muscles were hypertrophied in all cases examined, as was the interventricular septum. With ventricular systole, the hypertrophied papillary muscle projected out towards the septum. Consequently, the mitral apparatus showed abnormal motion classified into two types (I and II), with an allowance for slight individual differences.

Type I: The mitral chordae tendineae were shifted towards the septum (Fig. 1A). The M-mode echocardiogram was recorded by an ultrasound beam which passed through these anteriorly shifted chordal echoes in the two dimensional image. The echoes of the anteriorly shifted chordae showed the systolic anterior motion in the M-mode echocardiogram (Fig. 1A and 1B). The echoes of the papillary muscles also contributed to systolic anterior motion (Fig. 1C). In this case the mitral leaflets were noted separately from the 

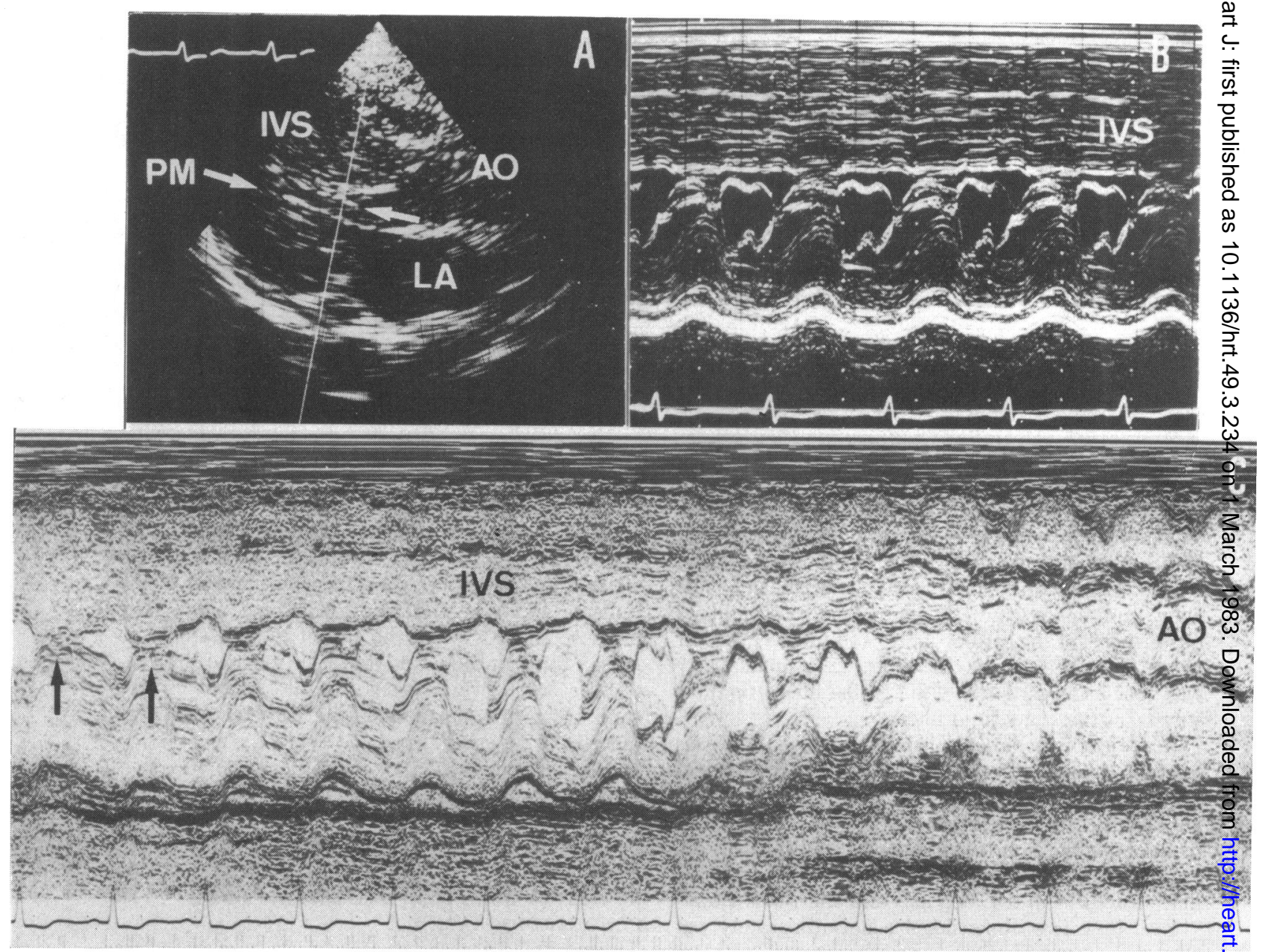

Fig. 1 Systolic anterior motion of type I mitral echo. (A) Long axis view of the left ventricle in mid-systole. The timing is shown as a short break on the electrocardiographic curve on the left top of this picture. IVS, interventricular septum; PM, papillary muscle; $A O$, aorta; $L A$, left atrium. The mitral chordae are shifted anteriorly following the papillary muscle projecting out toward the septum (white arrow). The mitral leaflet is almost in the conventional position. The white line in the middle of this view shows the beam direction for the $M$-mode echocardiogram in $(B)$. (B) $M$-mode echocardiogram recorded by an ultrasound beam in the direction shown in $(A)$. The systolic anterior motion of the mitral echo is well seen. There is a good correspondence between the echo lines showing the systolic anterior motion and the anteriorly shifted chordal echoes in $(A)$. (C) M-mode scanning echocardiogram recorded in the same range as the long axis view in $(A)$. The papillary muscle (black arrows) takes part in the formation of the distal part of the systolic anterior motion.

anteriorly shifted chordae tendineae and showed an almost normal orientation.

Type II: The hypertrophied and maloriented papillary muscle projected out into the ventricular cavity in early systole, almost coming into contact with the interventricular septum. In the moving images, the anterior leaflet closed, and then the posterior leaflet was lifted anterosuperiorly toward the septum (Fig. 2A). In this way, in the moving images, the posterior leaflet appeared to be carried up toward the subaortic region by the ejection flow. The orientation of the posterior leaflet, however, appeared to be ultimately determined by the maloriented papillary muscle (Fig. 2A). The posterior leaflet was directed anterosuperiorly and had a different orientation from the normal anteroinferior direction. The distal part of the anterior leaflet appeared to overlap the posterior leaflet, as it was bent anteriorly. Both leaflets were oriented so that they intersected the left ventricular outflow tract. The echoes of the papillary muscle and 

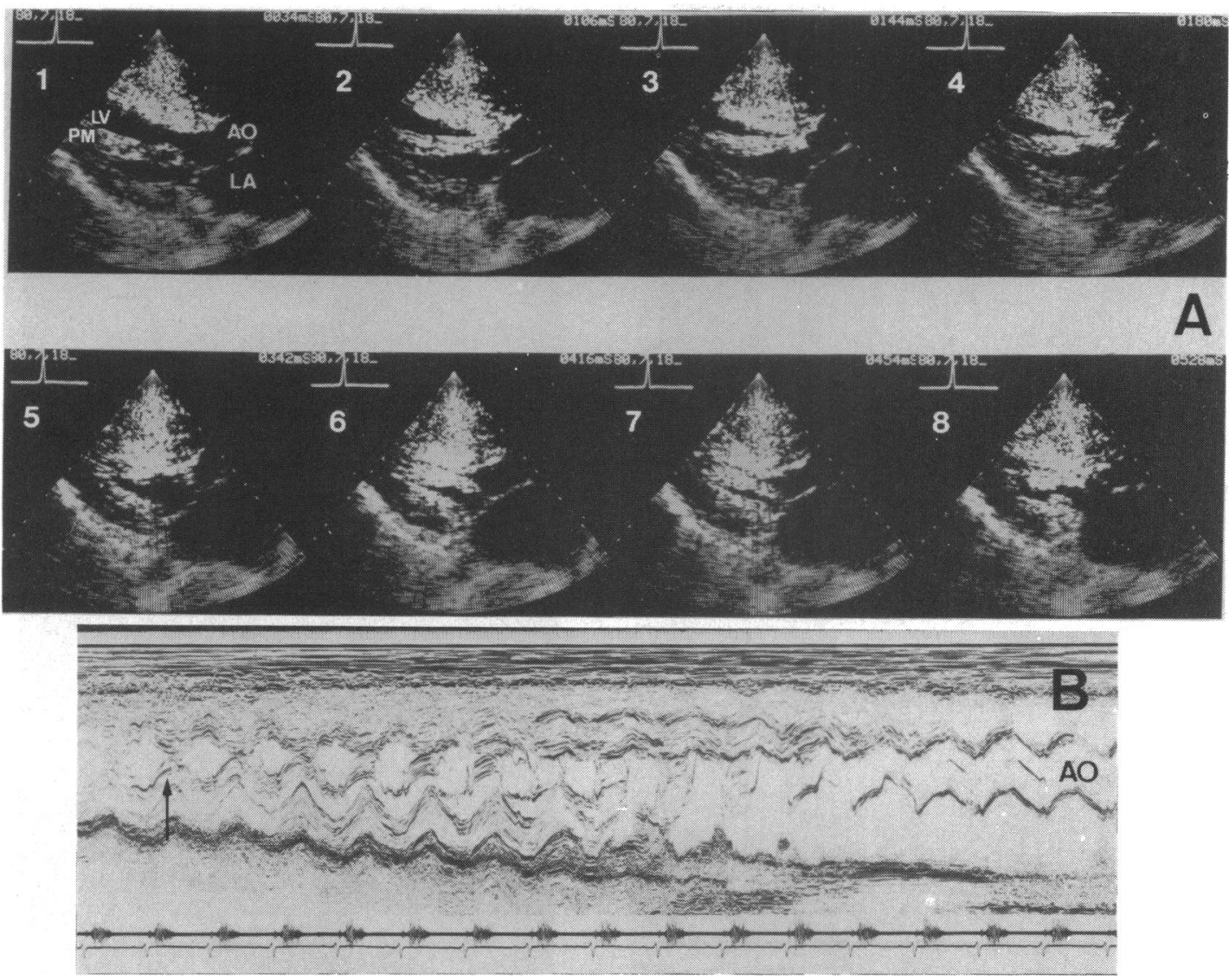

Fig. 2 Systolic anterior motion of type II mitral echo. (A) Serial long axis views of the development of systolic anterior motion. $L V$, left ventricle; $A O$, aorta; PM, papillary muscle; LA, left atrium. (1) The remarkably hypertrophied posteromedial papillary muscle projects out toward the interventricular septum, pulling the posterior mitral leaflet anterosuperiorly. (2) to (4) The tip of the papillary muscle is in contact with the septum and the posterior mitral leaflet appears to be pushed slightly towards the subaortic region by the ejection flow. (5) The papillary muscle is in close contact with the septum; the posterior mitral leaflet is directed anterosuperiorly; the chordae and posterior leaflet probably with the distal part of the anterior leaflet appear to intersect the outflow tract. (6) and (7) The axis of the papillary muscle is changing from anterosuperior to posterosuperior, separating the tip of the papillary muscle and the chordae and leaflets from the septum. (8) The mitral valve opens. (B) M-mode scanning echocardiogram recorded in the same range as the long axis view in $(A)$. The distal part of the systolic anterior motion (black arrow) is thought to consist of the papillary muscle echo.

mitral apparatus showed the systolic anterior motion in the M-mode echocardiogram (Fig. 2B and Fig. 3A, B). The points of attachment of the chordae to the leaflets were not always recognised. The orientation of the mitral leaflets obstructing the outflow tract was clearly seen, however, in the long axis view at the central part of the left ventricle, which involved neither chordae nor papillary muscle.

In the latter half of systole, the orientation of the papillary muscle changed as the apical part of the ventricle contracted, so that the direction of the axis of the papillary muscle shifted from anterosuperior to posterosuperior, moving the tip away from the septum (Fig. 2A). This change in the orientation of the papillary muscle in late systole was common to both types I and II.

Type I systolic anterior motion was seen in seven cases and type II in six cases (Table). Classification of type was not possible in two cases, however, because of the complexities of echoes in the area. These two cases appeared to be intermediate between type I and type II, linking the two types in an apparent continuous spectrum.

The abnormal systolic orientation of the papillary 

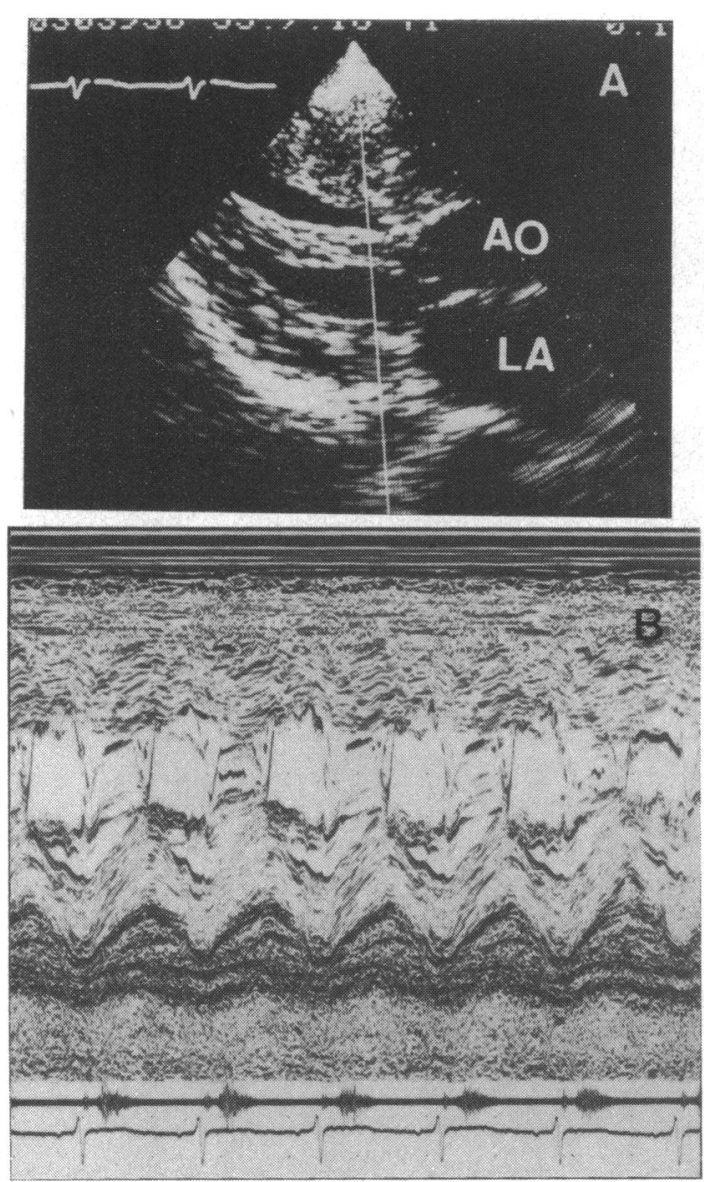

Fig. 3 Systolic anterior motion of type II mitral echo. (A) Long axis view of the left ventricle in mid-systole. The white line in the middle of this view shows the beam direction for the $M$-mode echocardiogram in (B). (B) M-mode echocardiogram recorded by an ultrasound beam in the direction shown in $(A)$. The systolic anterior motion of the mitral echo is seen.

muscle was seen in both papillary muscles in eight cases, mainly in the anterior muscle in five cases, and in the posterior muscle in two cases. In cases of only one abnormally oriented papillary muscle, the chordae and mitral leaflets were shifted towards the septum only on that side, so that the outflow was narrowed mainly on the same side. This event was clearly seen in the short axis view (Fig. 4).

\section{RELATIONS BETWEEN SYSTOLIC ANTERIOR}

MOTION IN M-MODE ECHOCARDIOGRAM AND SITES OF INTRAVENTRICULAR PRESSURE GRADIENT

Site of intraventricular pressure gradient in type I cases There was an intraventricular pressure gradient in
Nagata, Nimura, Beppu, Park, Sakakibara $\underset{\oplus}{\stackrel{T}{\odot}}$

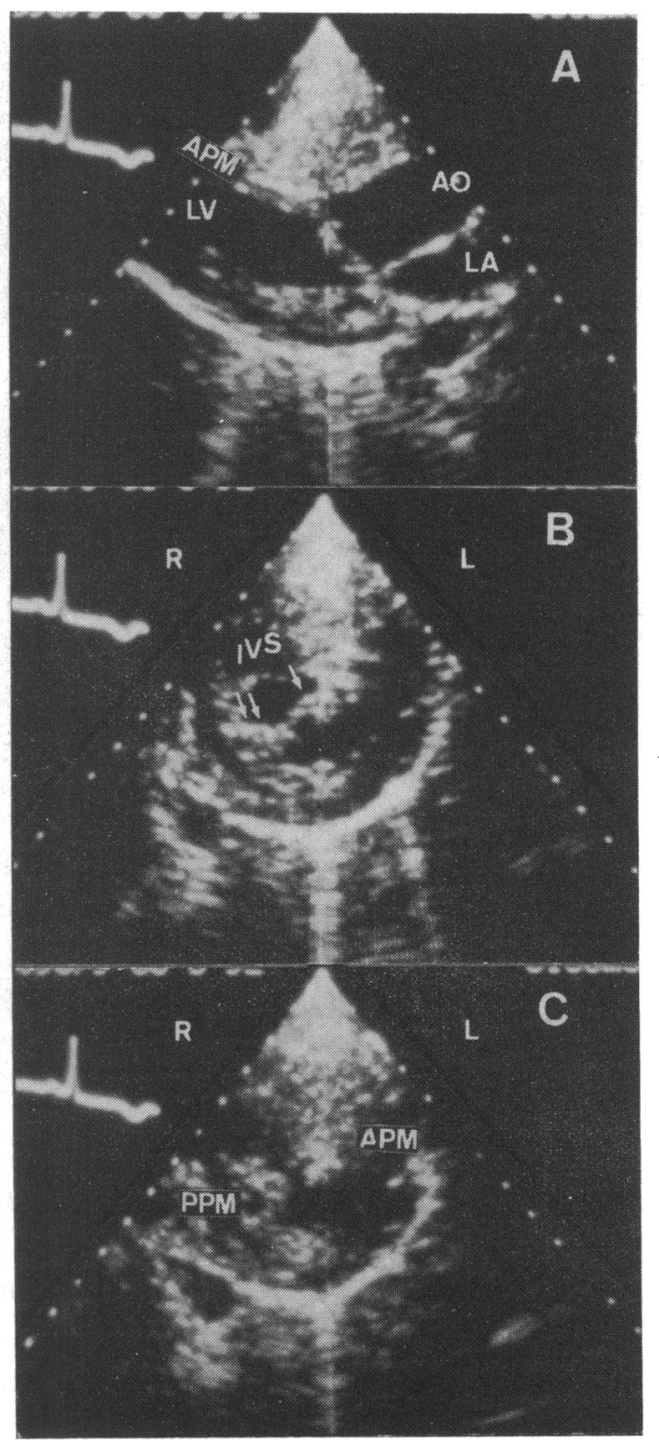

Fig. 4 Partial obstruction of the left ventricular outflow tract by the mitral leaflets. APM, anterior papillary muscle; $L V$, left ventricle; $A O$, aorta; $L A$, left atrium; PPM, posterior papillary $N$ muscle; IVS, interventricular septum. (A) Long axis view. The anterior papillary muscle is in close contact with the

interventricular septum, pulling the mitral chordae and leaflets anteriorly. (B) Short axis view at the level of the mitral leaflets. The left lateral parts of the mitral leaflets are anteriorly displaced, and thus are in contact with the interventricular septum (single arrow). The right medial parts are noted, however, in the ordinary closed position (two arrows), leaving a cavity between them and the septum. (C) Short axis view at the level of the papillary muscles. The anterior papillary muscle is displaced anteriorly, causing it to be in contact with the septum, while the posterior papillary muscle is nearly in the usual position. 


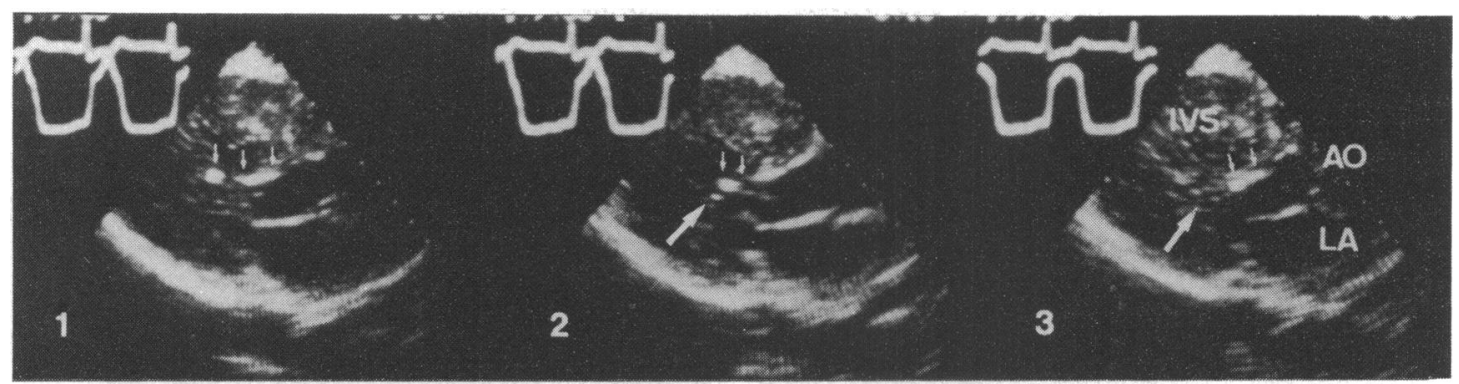

Fig. 5 Intraventricular pressure gradient in type I systolic anterior motion. The catheter with the Millar micro-tip pressure transducer is indicated by small white arrows. The intraventricular pressure is displayed in the upper left comer of each frame. (1) When the catheter tip nears the apex through the papillary muscle level, a high pressure is shown. (2) It is at the level of the tip of the papillary muscle (big arrow). (3) When it is pulled up to the suprapapillary level, a sudden drop of pressure of $50 \mathrm{~mm} H \mathrm{~g}$ is seen. In this case, the site of pressure gradient is at the papillary muscle level.

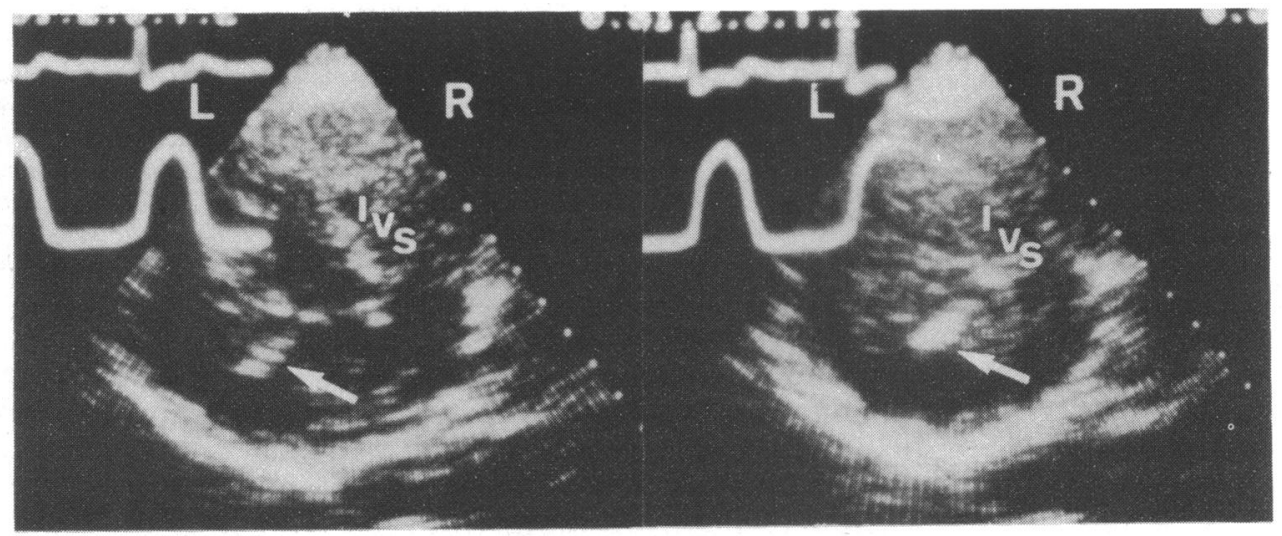

Fig. 6 Catheter entrapped in the trabeculae of the left ventricular inflow part near the base. Short axis view at the suprapapillary level in diastole on the left and that in systole on the right. The catheter inserted from the aorta easily enters posteriorly into the inflow portion. Onfluoroscopy in the anteroposterior position it appears to be in the apex. It moves freely in the ventricular cavity with the heart beat. When entrapped, however, it moves only in synchrony with the left ventricular wall. IVS, interventricular septum.

four of the seven cases of type 1 (cases 1, 2,3, and 4, Table). When the catheter tip was in the apical cavity, a high pressure was shown. When the catheter tip was pulled back through the papillary muscle level, the pressure suddenly dropped (Fig. 5). The suprapapillary part of the outflow tract and the inflow tract, that is the posterobasal part of the left ventricular cavity, showed a low pressure. Therefore, in these cases, the site of the intraventricular pressure gradient was at the papillary muscle level.

In the other three cases of type I (cases 5,6, and 7), it was impossible to advance the catheter into the apical cavity beyond the papillary muscle level, and it remained in the low pressure zones. In cases 6 and 7 , the catheter showed a high pressure when the tip appeared to be in the apical cavity, as seen by fluoroscopy. Real time two dimensional echocardiography showed, however, that the catheter tip was not in the apical cavity, but in the posterobasal part of the cavity (Fig. 6). When the catheter tip was moved away from the posterior wall, the pressure fell suddenly to normal. This high pressure was, therefore, considered to be a false positive caused by the entrapment of the catheter tip by the trabeculae of the posterior wall.

Site of intraventricular pressure gradient in type II cases There were eight cases of type II, arbitrarily including the two intermediate cases (Table). In these, both anterior and posterior mitral leaflets appeared to be oriented in such a manner as to intersect the left ventricular outflow tract. A pressure gradient was noted at the level of the mitral leaflets in five of the eight (Fig. 7). The outflow tract distal to the mitral leaflets showed a low pressure and that proximal to the mitral leaflets a high pressure. The inflow part also had a high pressure, in contrast to that in the type I cases 

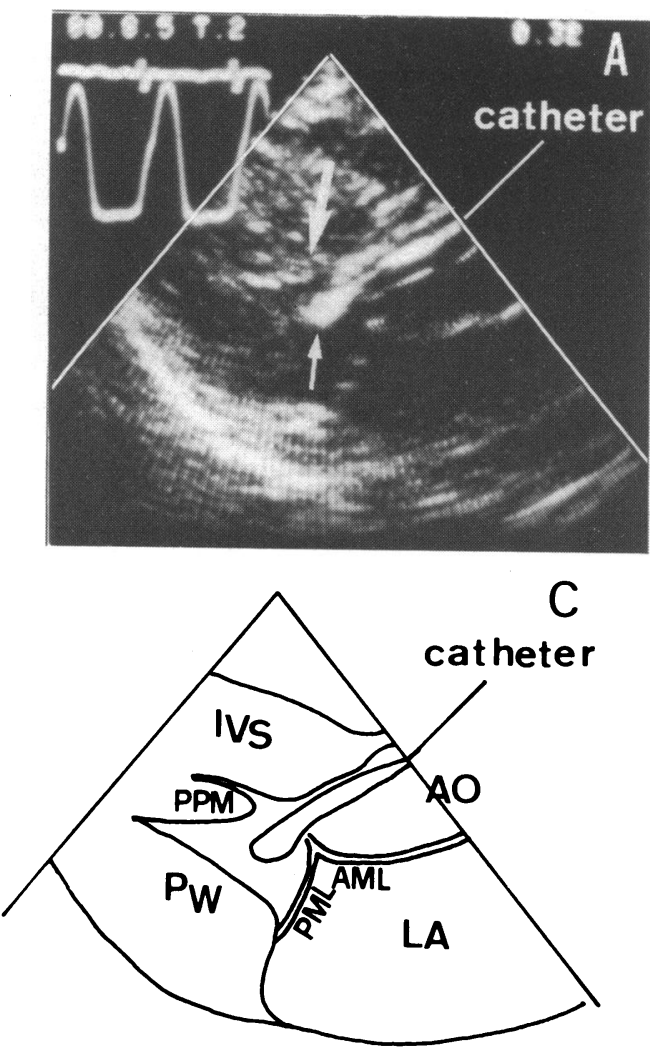

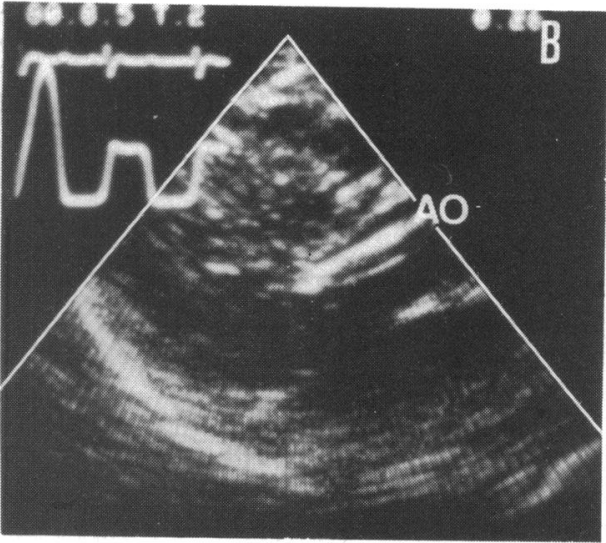

Fig. 7 Intraventricular pressure gradient in type II systolic anterior motion. This patient is the same as that in Fig. 2. (A) and $(C)$ The catheter tip is inserted across the mitral leaflets which obstruct the outflow tract of the left ventricle. There is a high pressure in the suprapapillary outflow tract and the inflow part. The small arrow indicates the catheter tip and the large one indicates the tip of the papillary muscle. (B) When the catheter tip is pulled back across the mitral leaflet level, there is a sudden drop in pressure. In this case, the site of the pressure gradient is across the mitral leaflets which obstruct the outflow tract.
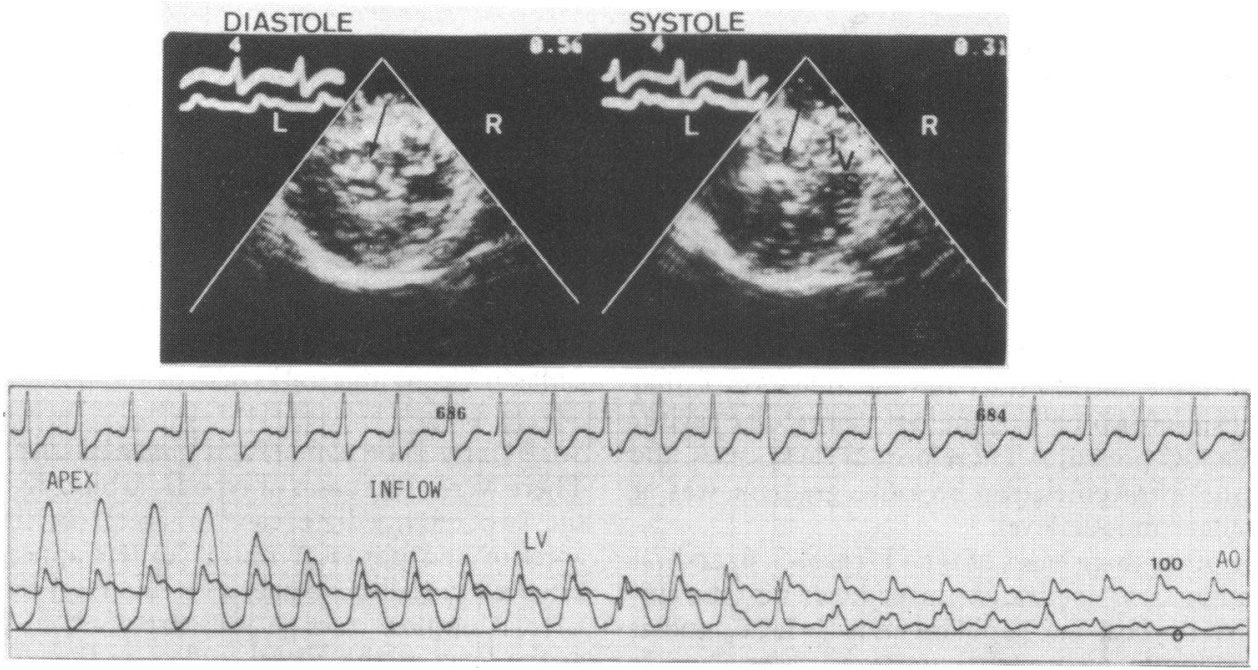

Fig. 8 Two sites of intraventricular pressure gradient, at the papillary muscle level and at the mitral leaflet level. The catheter was inserted from the left atrium into the apical cavity. The position of the catheter tip is noted in the short axis views (black arrow). When the catheter is pulled back through the papillary muscle level, there is a sudden drop of pressure $(90 \mathrm{mmHg})$. The pressure in the inflow part is still higher than that in the aorta. It is evident that there are two sites of pressure gradient, at papillary muscle level and at mitral leaflet level. 
which had low pressures. In the remaining three cases, there was no pressure gradient at the level of the mitral leaflets.

In the type II cases, the catheter was not advanced beyond the papillary muscle level into the apical cavity because of the difficulties of manoeuvrability and the hazard of provoking ventricular tachyarrhythmias, except in one patient (case 13 in Table) who had an intraventricular pressure gradient of $86 \mathrm{mmHg}$ at the mitral leaflet level before operation. The pressure was not measured at the papillary muscle level before operation, for the reasons already given (Table), and the patient underwent septal myo- and myectomy; mild systolic anterior motion of the mitral echo remained after the procedure. During this operation, the intracavitary pressure was measured by a catheter inserted from the left atrium immediately after myoand myectomy. The pressure in the posterobasal inflow part still remained higher than the aortic pressure by $30 \mathrm{mmHg}$. The catheter was advanced through the papillary muscle level into the apical region, showing another pressure gradient of $90 \mathrm{mmHg}$ at the papillary muscle level (Fig. 8).

Thus, though there are no data on the other patients in this group, it is likely that they too may have gradients elsewhere within the ventricle, probably at papillary muscle level.

\section{Discussion}

ROLES OF MITRAL LEAFLETS, CHORDAE, AND PAPILLARY MUSCLES IN DEVELOPING SYSTOLIC ANTERIOR MOTION OF MITRAL VALVE

There have been several studies on the echo source of anterior systolic motion by two dimensional echocardiography. Some of them ${ }^{3-10}$ showed that the echo sources of the systolic anterior motion were the mitral chordae tendineae which were anteriorly shifted by the malorientation of the inappropriately hypertrophied papillary muscles in systole. The others ${ }^{11-13}$ showed that the distal part of the anterior mitral leaflet was oriented perpendicularly to the interventricular septum in systole, showing the systolic anterior motion on the M-mode echocardiogram. Relations between these chordae and leaflet theories, however, had not been clarified hitherto.

In the present study, the improvement of the image quality in real time two dimensional echocardiography enabled us to develop a systematic concept of the role of the mitral leaflets, chordae, and papillary muscles in the formation of systolic anterior motion. Systolic anterior motion in the M-mode echocardiogram was classified into two types by real time two dimensional echocardiography. In type I, the chordae were the source of the abnormal echo, probably aided by the tip of the papillary muscle. In type II, the mitral leaflets, chordae, and tip of the papillary muscle were the sources. Here, it must be emphasised that the posterior leaflet also plays a role in developing systolic anterior motion, as well as the anterior leaflet and chordae. The two types are barely differentiated from each other in the M-mode echocardiogram.

Hypertrophy of the papillary muscles is always observed in hypertrophic obstructive cardiomyopathy. 6714 In the present study, it was seen that as systolic anterior motion developed the chordae and leaflets tended to be carried toward the subaortic region by the flow of ejection. There may be many factors involved in causing systolic anterior motion of the mitral echo, 6910 but it appeared to be ultimately determined by the malorientation of the inappropriately hypertrophied papillary muscles.

Systolic anterior motion did not necessarily develop uniformly on the anterolateral and posteromedial sides of the mitral leaflets. ${ }^{714} \mathrm{We}$ have reported already that hypertrophy does not always occur uniformly in both papillary muscles, but may be more prominent in one. ${ }^{71014}$ In the present study, we have shown that the anterior displacement of the mitral leaflets occurred particularly on the same side as the greater abnormality of the papillary muscle. Thus, the malorientation of the hypertrophied papillary muscles appear to be the most important factor among many in both types I and II. These two types seem to form a continuous spectrum. There were patients who appeared to be intermediate in type; but both were never found in the same patient at different times. The difference between the two types may be a matter of the degree of abnormality in the papillary muscles.

RECESSION OF SYSTOLIC ANTERIOR MOTION IN LATE SYSTOLE

In general, systolic anterior motion diminishes in late systole on the M-mode echocardiogram. The reason for this is unknown. We had previously speculated, on the basis of two dimensional echocardiographic findings, that the base of the papillary muscle shifted anteriorly with the emptying of the apical cavity in late systole, so that the direction of the axis of the papillary muscle changed from anterosuperior to posterosuperior, resulting in the recession of the tip of the papillary muscle. ${ }^{7}$ Such a change in the axis of the papillary muscle was visualised using real time images in the present study, the tip of the papillary muscle and the mitral chordae and leaflets moving away from the septum.

\section{SITES OF INTRAVENTRICULAR PRESSURE GRADIENT}

An intraventricular pressure gradient was found at the papillary muscle level in four of the seven cases with 


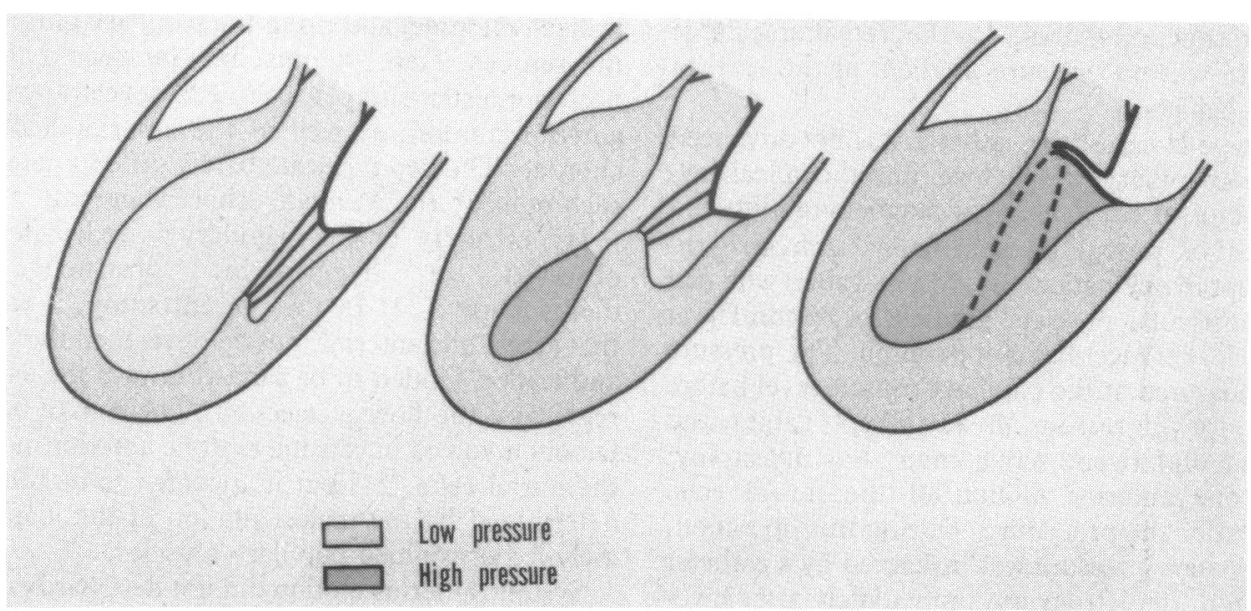

Fig. 9 Plan of left ventricular outflow obstruction in hypertrophic obstructive cardiomyopathy. Left: Normal long axis cross-section of the left ventricle. Middle: One or both hypertrophied papillary muscles project out towards the septum. The mitral chordae are shifted anteriorly, being manifested as systolic anterior motion (type I) in the $M$-mode. The papillary muscles occupy a large space, resulting in the development of intraventricular pressure gradient at their level. Right: One or both hypertrophied papillary muscles project out towards the septum. The mitral leaflets are lifted up anterosuperiorly, being manifested as systolic anterior motion (type II) in the M-mode. The anterosuperiorly lifted mitral leaflets are oriented in such a way as to dam up the outflow tract, resulting in the development of a pressure gradient across the leaflets.

type I systolic anterior motion. This kind of intraventricular pressure gradient had previously been reported by us. ${ }^{7}$ The enlarged papillary muscles project into the left ventricular cavity and occupy a large space. This makes the left ventricular cavity, already narrowed because of hypertrophy of the interventricular septum and other parts of the ventricular wall, even narrower at the level of the papillary muscles ${ }^{4} 7$ (Fig. 9 (middle)) and here it is worth noting that pressure was low in the inflow portion of the left ventricle as it was in the suprapapillary portion of the left ventricular outflow tract.

In five of the eight cases with type II systolic anterior motion, including the two intermediate cases, an intraventricular pressure gradient was observed across the mitral leaflets which were oriented in such a way as to intersect the left ventricular outflow tract. In the early stages of echocardiographic study of hypertrophic cardiomyopathy, Henry and coworkers, ${ }^{1}$ using a catheter inserted from the left atrium, observed a pressure higher than aortic in the inflow part of the left ventricle and they considered that the apposition of the anterior mitral leaflet to the interventricular septum was the cause. Further studies on the anatomical correlates of systolic anterior motion were needed. In the present study, the relation between the position of the mitral valve and the pressure gradient was clearly confirmed by the two dimensional images. The anterior and posterior mitral leaflets were oriented perpendicularly to intersect and thus obstruct the left ventricular outflow tract, causing a pressure gradient (Fig. 9 (right)) and, it should be emphasised, both leaflets participated. Furthermore, the inflow part of the left ventricle shows a high pressure compared with that in cases with type I systolic anterior motion.

The papillary muscle level was not searched for a pressure gradient in the cases of type II systolic anterior motion because of the technical difficulties and the hazards provoking ventricular tachyarrhythmias. As mentioned above, the cases with type II systolic anterior motion showed inappropriate hypertrophy of the papillary muscles, as did those with type I. It is therefore a possibility that some of the cases with type II systolic anterior motion have a pressure gradient at papillary muscle as well as at mitral leaflet level. This concept is supported by the findings during operation in case 13 , which probably had two sites of pressure gradient in the left ventricular cavity. In general, a characteristic feature of hypertrophy in hypertrophic cardiomyopathy is its nonuniformity, resulting in a bizarre-shaped ventricular cavity. 6715 Therefore, there may be not only one site of intraventricular pressure gradient, but two or more.

In the present study, some of the cases with type I systolic anterior motion showed no intraventricular pressure gradient at papillary muscle level, and some cases with type II systolic anterior motion showed none at mitral leaflet level. This is considered to be a matter of the degree of narrowing at the relevant 
levels in the ventricular cavity.

\section{SIGNIFICANCE OF REAL TIME TWO DIMENSIONAL ECHOCARDIOGRAPHY IN STUDY ON} INTRAVENTRICULAR PRESSURE GRADIENT IN HYPERTROPHIC OBSTRUCTIVE CARDIOMYOPATHY Real time two dimensional echocardiography was helpful as a local monitor in the study of the site of the intraventricular pressure gradient, as it produces images of the intraventricular structures, and was therefore useful in giving the relations between the tip of the catheter and the intracardiac structures. In this case, of course, care should be taken to keep the catheter tip within the cross-sectional plane, which is shallow, and to confirm the identity of its echo as described in the section on methods.

In hypertrophic obstructive cardiomyopathy, the shape of the ventricular cavity may be bizarre and it is often difficult to insert a catheter across the papillary muscle level into the apex. The catheter enters easily into the posterobasal part of the left ventricular cavity and, monitored on fluoroscopy in the anteroposterior projection, it may appear to reach the apex, as observed in cases 6 and 7. Thus, though there is a true pressure gradient at the papillary muscle level, the catheter fails to detect it. The two dimensional echocardiographic monitor can prevent such a false negative, because it enables the true position of the catheter tip to be recognised. It is also advantageous in preventing the recording of a false gradient caused by the entrapment of the catheter tip by the ventricular wall, as experienced also with cases 6 and 7. Thus, it is recommended that real time two dimensional echocardiography be used to ascertain the position of the catheter tip in the ventricular cavity for the intraventricular pressure studies in hypertrophic cardiomyopathy.

\section{References}

1 Henry - WL, Clark CE, Glancy DL, Epstein SE. Echocardiographic measurement of the left ventricular outflow gradient in idiopathic hypertrophic subaortic stenosis. $N$ Engl f Med 1973; 288: 989-93.

2 Rossen RM, Goodman DJ, Ingham RE, Popp RL. Echocardiographic criteria in the diagnosis of idiopathic hypertrophic subaortic stenosis. Circulation 1974; 50: 747-51.

3 Tanaka M, Kosaka S, Konno $\mathrm{K}$, et al. Ultrasound cardiogram in patients with idiopathic hypertrophic subaortic stenosis. Proceedings of the 24th Scientific Meeting of the Japan Society of Ultrasonics in Medicine. Tokyo: The Japan Society of Ultrasonics in Medicine, 1973: 95-96. (in Japanese)

4 Nimura Y, Sakakibara H, Matsuo H, et al. Studies on left ventricular anatomy and events in hypertrophic cardiomyopathy with ultrasonocardiotomography in special reference to obstructive signs. Shinzo 1975; 8: 1461-77. (in Japanese)

5 Nimura Y, Beppu S, Nagata S. Two dimensional echocardiography (ultrasonocardiotomography) in diagnosis of heart diseases. In: Kurjak A, ed. Recent advances in ultrasound diagnosis. Amsterdam: Excerpta Medica, 1978: 255-67.

6 Nagata S, Nimura Y. Anatomical and functional features of hypertrophied left ventricle studied with $M$-mode and real time cross-sectional echocardiographies. $\mathcal{F} p$ Circ $\mathcal{J}$ 1979; 43: 333-41.

7 Nimura Y, Nagata S, Sakakibara H, et al. Newer aspects in hypertrophic cardiomyopathy studied with crosssectional echocardiography. In: Sekiguchi M, Olsen EGJ, eds. Cardiomyopathy. Clinical, pathological and theoretical aspects. Tokyo: University Tokyo Press, and Baltimore: University Park Press, 1980: 13-27.

8 Kambe T, Hibi N, Nishimura K, et al. Real time observation of the echo source of systolic hump in hypertrophic obstructive cardiomyopathy with high speed ultrasonocardiotomography. Fpn Heart f 1977; 18: 74350.

9 Gehrke J, Goodwin JF. The significance of systolic anterior motion (SAM) on the mitral valve echo pattern in hypertrophic cardiomyopathy. Clin Cardiol 1978; 1: 337-45.

10 Rodger JC. Motion of mitral apparatus in hypertrophic cardiomyopathy with obstruction. Br Heart $\mathcal{F} 1976$; 38: 732-7.

11 Henry WL, Clark CE, Griffith JM, Epstein SE. Mechanism of left ventricular outflow obstruction in patients with obstructive asymmetric septal hypertrophy (idiopathic hypertrophic subaortic stenosis). Am $\mathcal{f}$ Cardiol 1975; 35: 337-45.

12 Maron BJ, Gottdiener JS, Roberts WC, Henry WL, Savage DD, Epstein SE. Left ventricular outflow tract obstruction due to systolic anterior motion of the anterior mitral leaflet in patients with concentric left ventricular hypertrophy. Circulation 1978; 57: 527-33.

13 Jinnouchi J, Koga Y, Yoshioka H, Sugi K, Toshima H. Mechanism of left ventricular outflow obstruction in patient with hypertrophic cardiomyopathy. Real time cross-sectional echocardiographic study. Shinzo 1978; 10: 498-506. (in Japanese)

14 Reis RL, Bolton MR, King JF, Pugh DM, Dunn MI, Mason DT. Anterior-superior displacement of papillary muscles producing obstruction and mitral regurgitation in idiopathic hypertrophic subaortic stenosis. Operative relief by posterior-superior realignment of papillary muscles following ventricular septal myectomy. Circulation 1974; 49 and 50: suppl II: 181-8.

15 Maron BJ, Gottdiener JS, Epstein SE. Patterns and significance of distribution of left ventricular hypertrophy in hypertrophic cardiomyopathy. A wide angle, two dimensional echocardiographic study of 125 patients. Am f Cardiol 1981; 48: 418-28.

Requests for reprints to Dr Seiki Nagata, Department of Medicine, Division of Cardiology, National Cardiovascular Center, 125 Fujishiro-dai 5-chome, Suita, Osaka 565, Japan. 